\title{
Trochlear-oculomotor synkinesis: another congenital cranial dysinnervation disorder?
}

\author{
Sincinesia troclear-oculomotora: outro distúrbio congênito \\ de denervação craniana?
}

Ian Curi ${ }^{1}$

1. Hospital Federal dos Servidores do Estado do Rio de Janeiro, Rio de Janeiro, RJ, Brazil.

\begin{abstract}
This report documents an unusual phenomenon. A 6-year-old girl with trochlear-oculomotor synkinesis presented with superior oblique and palpebral levator co-contraction. The literature was reviewed and the possibility of classifying this entity as a congenital cranial dysinnervation disorder was speculated.
\end{abstract}

Keywords: Synkinesis; Trochlear nerve; Cranial nerves/abnormalities; Oculomotor muscles; Ocular motility disorders/congenital; Case reports

RESUMO | Este relato descreve um fenômeno incomum. Uma menina de 6 anos com sincinesia troclear-oculomotora apresentou co-contração do oblíquo superior e do levantador da pálpebra. A literatura foi revisada e especulou-se a possibilidade de classificar essa desordem como um distúrbio da congenital cranial dysinnervation disorder.

Descritores: Sincinesia; Nervo troclear; Nervos cranianos/anormalidades; Músculos oculomotores; Transtornos da motilidade ocular/congênito; Relatos de casos

\section{INTRODUCTION}

Here the case of a 6-year-old girl who presented with a retraction of the upper eyelid while looking to the diagnostic position of superior oblique leading to the diagnosis of trochlear-oculomotor synkinesis was documented. Further, other cases sharing similar features were reviewed, focusing on the possibility of classifying this rare abnormal synkinesis as a congenital cranial dysinnervation disorder.

Submitted for publication: March 7, 2018

Accepted for publication: June 22, 2018

Funding: No specific financial support was available for this study.

Disclosure of potential conflicts of interest: The author have any potential conflicts of interest to disclose.

Corresponding author: Ian Curi

Rua Sacadura Cabral, 178 - Rio de Janeiro, RJ - 20221-903 - Brazil

E-mail: ianbonotto@gmail.com

\section{CASE REPORT}

A healthy 6-year-old girl presented at our hospital complaining of strange movements of her right superior eyelid that had persisted since birth. Prenatal care and delivery proceeded without abnormalities and there were no relevant remarks in the family history. In both eyes her visual acuity was 1.0 and cicloplegic refraction was +1.00 . Slit-lamp and fundoscopic examination revealed nothing remarkable. No pupillary defects were observed. In sensory evaluation, there was a stereopsis of $40 \mathrm{sec} / \mathrm{arc}$ in the Titmus test. In the primary position, there was a 2-mm right superior ptosis with normal function of the upper eyelid levator muscle. Evaluation of her ocular motility revealed normal ductions and versions and she was orthotropic in all fields of gaze; however, there was a slight widening of the palpebral fissure while adducting the right eye, which became very intense while looking down and inward due to the retraction of the right upper eyelid in the precise diagnostic position of the right superior oblique muscle (Figure 1). There was no lid retraction during chewing or performing any other jaw movement, but there was a clear co-contraction of the superior oblique and upper eyelid levator muscles. The family was reassured regarding the benign features of the case and advised to visit the doctor's office for follow-up once a year.

\section{DISCUSSION}

Synkinesis involving the nerves that supply the eye and their adnexa are not uncommon. However, in a case series, Freedmand and Kushner emphasized the absence of any prior reports of miswirings involving the trochlear nerve, highlighting that the abducens nerve is frequently involved on a congenital basis and the oculomotor nerve is sometimes involved in traumatic cases, although less frequently than the $\mathrm{VI}^{\text {th }}$ nerve ${ }^{(1)}$. 

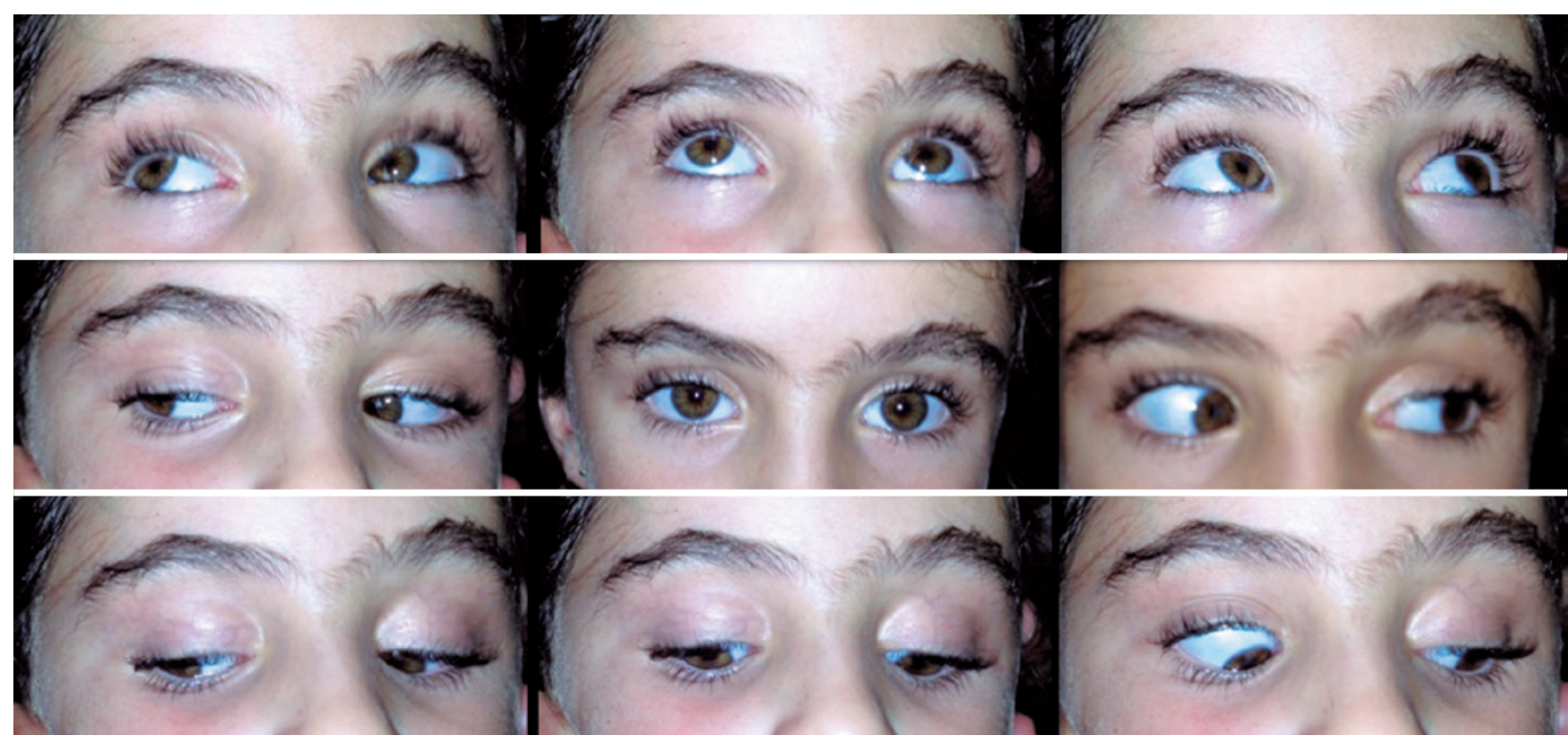

Figure 1. Nine gaze positions showing no limitations of ductions and versions. A slight widening of palpebral fissure in the adduction of the right eye, being very intense while looking down and inward, is due to the retraction of the right upper eyelid.

Since then trochlear-oculomotor synkinesis has been reported rarely. Martorina and Porte reported a case of a 4-year-old-girl with left congenital ptosis and maximum elevation of the lid while looking down and inward. They attributed this condition to a misdirection of regenerating fibers of the $\mathrm{III}^{\text {rd }}$ and IV th cranial nerve, probably secondary to an obstetrical trauma in a forceps-assisted delivery ${ }^{(2)}$.

Lim et al. reported a premature 4-year-old girl with tetralogy of Fallot. Although there was no ptosis and she was orthophoric in all gaze directions, she demonstrated left lid retraction on downgaze, more pronounced on the right downgaze ${ }^{(3)}$.

Kothari et al. demonstrated a more complex case in which a healthy 7-year-old boy had esophoria, left ptosis, excyclotorsion, limitation of elevation of the left eye, and left lid retraction when looking down and right. The authors suggested the cause as congenital paresis of the superior division of the left oculomotor nerve, resulting in aberrant innervation ${ }^{(4)}$. However, Pandey et al. suggested that the authors in this case had misdiagnosed what appeared rather to be a hallmark presentation of left congenital Brown syndrome with downshoot of the globe and widening of the palpebral fissure in adduction ${ }^{(5)}$.

Bursztyn and Makar described a 6-year-old boy with an otherwise normal ophthalmological examination, but a retraction of the right upper eyelid occurring while depressing the right eye in adduction. With magnetic resonance imaging of the brain, they observed a moderately sized right posterior communicating artery in contact with the right oculomotor nerve; although images do not allow observation of the $\mathrm{IV}^{\mathrm{th}}$ nerve, the authors speculated that this congenital anomaly may have been responsible for the misdirection in this case ${ }^{(6)}$.

This rarity is thought to be due to the distance of the trochlear nerve from the other cranial nerve roots, since the trochlear nerve is the only cranial nerve that decussates within the brainstem-and at the same time, the only one to exit the brainstem dorsally. Despite the fact that the levator and trochlear nuclei lie in a close proximity at brainstem, the former supplies innervation to both eyelids, while the latter, only to the contralateral superior oblique. Thus, if this synkinesis was central in origin, both eyelids should be involved. Because the closest peripherical proximity of both nerves is in the orbital appex, this is the place where the synkinesis most probably occurs ${ }^{(6)}$.

Congenital cranial dysinnervation disorders (CCDDs) are non-progressive, sporadic or familial developmental anomalies of the cranial nerves; they are characterized by abnormal eye, eyelid, and/or facial movements ${ }^{(7)}$. Congenital fibrosis of extra-ocular muscles (CFEOM), congenital ptosis, Duane Syndrome, horizontal gaze palsy with progressive scoliosis, congenital facial palsy, and 
Moebius syndrome are only few examples of $\mathrm{CCDDs}^{(7,8)}$ on a growing list in which many other disorders, such as Brown syndrome, Marcus Gunn jaw-winking synkinesis, synergistic divergence, and congenital IV th nerve palsy, are favored candidates, already being included in some series $^{(9)}$.

It is thus eminently reasonable to speculate that a synkinesis between the trochlear and oculomotor could fit the spectrum of CCDDs.

\section{REFERENCES}

1. Freedman HL, Kushner BJ. Congenital ocular aberrant innervation-new concepts. J Pediatr Ophthalmol Strabismus. 1997;34(1):10-6.

2. Martorina M, Porte E. [Congenital palpebral ptosiswithparadoxisóculo-palpebralsynkinesis]. J Fr Ophtalmol. 1986;9(4):281-4. French.
3. Lim KH, Lee SY, Hwang JM. Primary levatorsynkinesis associated with eye movement. J Pediatr Ophthalmol Strabismus. 2001;38(3): 179-80.

4. Kothari M, Hussain A, Kar D, Toshniwal S. Primary superior oblique muscle-levator muscle synkinesis. J AAPOS. 2007;11(2):204-5. Comment in: J AAPOS. 2012;16(2):214-5; author reply 215-6.

5. Pandey PK, Rathi N, Singh A, Sharma A, Shinde V, Sharma S, et AL. Primary superior oblique muscle-levator muscle synkinesis. J AAPOS. 2012;16(2):214-5; author reply 215-6.

6. Bursztyn LL, Makar I. Congenital trochlear-oculomotor synkinesis. J Neuroophthalmol. 2014;34(1):64-6.

7. Singh A, Pandey PK, Agrawal A, Mittal SK, Rana KM, Bahuguna C. Congenital cranial dysinnervation disorders. Int Ophthalmol. 2017;37(6):1369-81.

8. Fels R. Congenital cranial dysinnervation disorders: a literature review. AmOrthopt J. 2017;67(1):89-92.

9. Coussens T, Ellis FJ. Considerations on the etiology of congenital Brown syndrome. Curr Opin Ophthalmol. 2015;26(5):357-61. 